\title{
Pauses and reversals of infant mortality decline in India in 2017 and 2018
}

\author{
Jean Drèze Aashish Gupta Sai Ankit Parashar Kanika Sharma
}

November 8, 2020

\begin{abstract}
This note examines recent trends in infant mortality in India, based on summary reports from the Sample Registration System (SRS). We find evidence of slowdown, pauses, and reversals in infant mortality decline in large parts of India in 2017 and 2018, the last two years for which SRS data are available. In urban areas, the infant mortality rate stagnated at 23 deaths per 1,000 births between 2016 and 2018. Worse, overall infant mortality increased in the poorer states of Chhattisgarh, Jharkhand, Madhya Pradesh, and Uttar Pradesh in this period. This occurred despite sustained improvements in household access to sanitation and clean fuel. One possible interpretation of these findings is that, in addition to their impact on unemployment and poverty, the demonetization experiment in late 2016 and the subsequent economic slowdown had an adverse effect on child health. In any case, these trends reinforce earlier evidence of faltering human development in India in recent years.
\end{abstract}

Keywords: Infant mortality, health, human development, demonetisation, India.

*Jean Drèze (jean@econdse.org) is at Ranchi University, Aashish Gupta (aashishg@sas.upenn.edu) at the University of Pennsylvania, Sai Ankit Parashar (ankitp654@gmail.com) at the Tata Institute of Social Sciences, Tuljapur, and Kanika Sharma (kanika.sharma@emory.edu) at Emory University. For helpful comments and suggestions, we are grateful to Jere Behrman, Pritha Chatterjee, Diane Coffey, Patrick Gerland, Michel Guillot, Payal Hathi, Avinash Kishore, Nikhil Srivastav, Nikkil Sudharsanan, Sangita Vyas, and Anumeha Yadav. Aashish Gupta was supported by the IUSSP CRVS fellowship. 


\section{Introduction}

In historical perspective, the last few decades have been a time of rapid health improvements in developing countries (Hill et al., 2012; Deaton, 2013; Rosling et al., 2019). In India, for instance, 129 out of every 1,000 infants died before reaching their first birthday in 1971, when the Sample Registration System (SRS) started monitoring mortality (ORGI, 2016a). Four decades later, in 2011, infant mortality had declined to about 44 deaths per 1,000 live births. However, these improvements are not continuous or automatic. Pauses and even reversals in mortality decline have been observed. ${ }^{1}$ In this note, we present evidence of slowdown, pauses, and reversals of infant mortality decline in large parts of India in 2017 and 2018, based on recently released reports from the SRS.

The SRS is a country-wide survey which tracks vital events in a panel of villages and urban blocks (Mahapatra, 2017). Annual estimates of infant mortality from the SRS are representative at the national level and for the larger states. Since individual level data from the SRS are not available to researchers, we follow the previous literature (Saikia et al., 2010; Drèze and Sen, 2013; Canudas-Romo et al., 2016) and use reported infant mortality rates from annual reports, bulletins, and compendiums published by the SRS (ORGI, 2016a; ORGI, 2020). The most recent estimates in the public domain are for 2018.

Briefly, we find that India's infant mortality rate (IMR) stagnated in urban areas in 2017 and 2018. Further, overall infant mortality increased in the states of Chhattisgarh, Jharkhand, Madhya Pradesh, and Uttar Pradesh, while stagnating for at least a year in seven other states. This sort of faltering of IMR decline has not been observed in the SRS for many years. It is all the more alarming as it occurred at a time of rapid improvement in environmental determinants of health such as sanitation and LPG access (Gupta et al., $2020 a, b)$. One possible reason for this setback is that, aside from its adverse effects on poverty and employment (Vyas, 2018; Jha, 2019a,b; Subramanian, 2020), India's shock

demonetization in November 2016 and the subsequent economic disruption also had a negative impact on child health.

\section{The Facts}

Figure 1 shows trends in the infant mortality rate at the all-India level (solid blue line), for urban areas (red long-dashes), and for rural areas (dashed green line). Two patterns are worth noting. First, before 2005, year-to-year fluctuations - including short-term in- 
creases - in infant mortality were common. These fluctuations occurred when the SRS panel was revised (in years indicated by the vertical lines), but also otherwise, for instance in the early 1970s when the SRS was being put into place. ${ }^{2}$ However, from 2005 onwards, IMR declined monotonically in rural as well as urban areas, year after year, until 2016. Second, the pace of IMR decline was faster in 2005-16 than in earlier periods. Between 2005 and 2016, the annual rate of decline in overall IMR (estimated by semi-log regression of IMR on time) was 4.8\% per year, compared with $2.1 \%$ per year in 1990-2005 and 2.6\% per year in 1971-1990. After 2016, however, declines were modest again: the all-India IMR declined by $2.9 \%$ in 2017 and 3.1\% in 2018.

Considering the pattern of steady and rapid decline between 2005 and 2016, IMR levels in 2017 and 2018 are unusual. Had the 2005-2016 trend decline continued till 2018, we would have seen lower infant mortality rates in those years. Instead, between 2016 and 2018, urban IMR stagnated, and the rate of decline of rural and overall IMR slowed down.

The slowdown is even clearer if we focus on age-specific mortality rates in the $0-1$ age group instead of the infant mortality rate, as shown in Appendix Figure A1. Age-specific mortality rates $\left({ }_{n} m_{x}\right)$ reflect period mortality conditions better than the infant mortality rate (Preston et al., 2001). ${ }^{3}$ In contrast with the steady decline that preceded, age-specific mortality in the 0-1 age group was much the same in 2018 as in 2016, not only in urban areas but also in rural areas. Unfortunately, we were unable to construct a longer timeseries for age-specific mortality rates.

Figure 2 shows trends in the infant mortality rate for the bigger states for three decades, from 1988 to $2018 .{ }^{4}$ In these panels, a red line indicates that IMR faltered (i.e. stagnated or increased) in 2017 or 2018 or both years, compared with the previous year. Infant mortality faltered in 8 of these 20 states in 2017. In 2018, it faltered in 6 states, including four (Chhattisgarh, Jharkhand, Madhya Pradesh, and Uttar Pradesh) where IMR increased. In Chhattisgarh, Jharkhand and Madhya Pradesh, the IMR was higher in 2018 than two years earlier, and in Uttar Pradesh it was the same. ${ }^{5}$ While faltering in a specific state and year is not usual (as can be seen from the occasional "wobbling" of IMR in these figures), there is no precedent of such widespread faltering in the recent past, even in a single year. To find another year where IMR faltered in at least 6 states, or where it increased in at least 4 states, we have to go back to 2006 and 2005 respectively. ${ }^{6}$ In the intervening period, IMR faltered in just one or two states (if any) in most years.

State-wise estimates for rural and urban areas are shown in Appendix Figures A2 and 
A3 respectively. As expected from the all-India findings, stagnation or declines of infant mortality in either 2017 or 2018 were more common in urban areas (15 states out of 20) than rural areas (9 states out of 20). These two sets of states account for $78.5 \%$ of India's urban population and $49.5 \%$ of India's rural population respectively. The states where overall IMR faltered in 2017 or 2018 constitute 56.4\% of India's population (ORGI, 2013).

Figure 3 further illustrates the fact that 2017 and 2018 departed from recent patterns. It compares infant mortality in a year and state with infant mortality in the next year. The three successive rows focus on total, rural and urban infant mortality rates respectively. Column 1 figures compare 2016 with 2015, column 2 compares 2017 with 2016, and column 3 compares 2018 with 2017. Each of the graphs has a $45^{\circ}$-line. Points above this line, or on the line, shown as red squares, indicate that infant mortality did not decline. Points below the line, shown as blue diamonds, indicate that infant mortality declined. Solid squares and diamonds are for India, and hollow squares and diamonds are for states. Comparing 2016 with 2015 (figures in column 1), infant mortality declined in most states. However, comparing 2017 with 2016, we observe increases in IMR, particularly in urban areas. By 2018, we see that IMR increases had spread to rural areas as well (column 3). These graphs also show that infant mortality increased mainly in states where it was already relatively high.

\section{Discussion}

This short note shows that the decline of infant mortality rates slowed down at the allIndia level in 2017 and 2018, halted in urban areas, and even reversed in some states. There is no precedent of this sort of setback in the progress of child health in India during the last 15 years. In 2017, reversals of infant mortality decline at the state level were largely confined to urban areas, but in 2018 similar reversals also happened in rural areas in several states. ${ }^{7}$

Prior to that, in 2005-2016, India experienced a long spell of rapid decline in infant mortality rates. That was a period of fast economic growth combined with some major initiatives in the social sector, including the launch of the National Rural Health Mission in 2005 and the gradual universalization of Integrated Child Development Services (ICDS) from 2006 onwards. There are many indications of substantial improvement in living conditions in that period, including a decline of close to $50 \%$ in multidimensional poverty (Alkire et al., 2018). 
The data we have presented add to earlier evidence that something went wrong after 2016. National Sample Survey data for 2017-18, for instance, suggest an unprecedented decline in real per-capita expenditure compared with 2011-12 (Subramanian, 2020). While this may not be due to a decline in the survey year itself, that is certainly a possibility, since the Indian economy was doing very well in the intervening period. Another worrying pattern is the virtual stagnation of real wages in rural areas between 2014-15 and 2018-19, in sharp contrast with the preceding 10 years when they were rising steadily(Anon, 2019; Narayanan, 2020, Figure 1).

One plausible hypothesis is that these setbacks are at least partly attributable to India's startling experiment with wholesale demonetization in November 2016, when 86\% of the currency became worthless overnight (Reddy, 2019). According to official estimates, India's real GDP continued to grow at a rapid rate in 2017-18 and 2018-19 (7.0\% and $6.1 \%$ respectively), but these estimates have come under considerable suspicion, and there is much evidence of a crisis of employment and livelihoods in the aftermath of demonetization (Drèze et al., 2016; Vyas, 2018; Reddy, 2019). How long it lasted is hard to tell, but it is possible that the crisis lasted long enough to affect infant mortality rates in 2017 and 2018. Perhaps the picture will become clearer as further data emerge. ${ }^{8}$ India's statistical system, alas, has significantly deteriorated lately. ${ }^{9}$

Hopefully, the decline of infant mortality picked up again in 2019, but another setback is likely to take place this year, in 2020, due to the Covid-19 crisis. The national lockdown in April-May 2020 led to mass unemployment and a major disruption of public services, including routine health services such as antenatal care and child immunization (Rukmini S, 2020; Drèze, 2020; Drèze and Paikra, 2020). As the end of the year approaches, economic recovery is still far from complete. In short, there is a distinct possibility that three of the last four years will turn out to be bleak times for infant mortality decline in India, particularly in urban areas. 


\section{Notes}

${ }^{1}$ Mortality increases have been associated, for instance, with AIDS and rising homicides among Blacks in the US in the 1980s (Kochanek et al., 1994), psychological shocks and alcohol consumption in Russia after the collapse of the USSR (Shkolnikov et al., 1998), sanctions and the Gulf war in Iraq (Drèze and Gazdar, 1992; Ascherio et al., 1992), the AIDS epidemic in Sub-Saharan Africa (Reniers et al., 2011), and deaths from drug overdoses and injury-related causes in the United States recently (Ho and Hendi, 2018).

${ }^{2}$ The SRS sampling frames were revised in 1977-78, 1983-85, 1993-95, 2004, and 2014 (ORGI, 2016b). These revisions were based on the results of the decennial censuses. Fluctuations in mortality trends after revisions have previously been documented (Bhat, 2002; Gerland, 2014).

${ }^{3}$ The age-specific mortality rate in the $0-1$ age group is defined as the number of deaths in that age group divided by the number of person-years lived in that age group (often approximated by the number of children aged 0-1 in the middle of the year). The infant mortality rate uses a different denominator - the number of births in the reference year. While the IMR is commonly interpreted as the probability of dying before age 1 , that is not quite correct, since the deaths in the numerator and the births in the denominator pertain to different (overlapping) cohorts of children. It is only when the number of births is constant over time that this interpretation holds.

4"Bigger States" are as defined by the SRS bulletins from the years 2015-2018, except Delhi.

${ }^{5}$ The annual IMR figures for 2015, 2016, 2017 and 2018 were as follows. Chhattisgarh: 41, 39, 38, 41. Jharkhand: 32, 29, 29, 30. Madhya Pradesh: 50, 47, 46, 48. Uttar Pradesh 46, 43, 41, 43.

${ }^{6} \mathrm{~A}$ part of the explanation for increases in 2005 could be the revision of the SRS sampling frame in 2004.

${ }^{7}$ It is not clear why the slowdown of mortality decline in 2017 and 2018 was more pronounced in urban areas. One possibility is that rural areas were less affected, initially at least, by the demonetisation experiment in 2016 (discussed further on), because the rural economy is less dependent on cash. Quite likely, rural areas also benefited more from continued improvements in environmental determinants of health, such as sanitation and clean-fuel access.

${ }^{8}$ Unit-level SRS data, if released, or data from Phase-1 states of the National Family Health Survey5 , would be useful to better understand these patterns. Accurate clustered standard errors can also be calculated from unit-level SRS data.

${ }^{9}$ This applies inter-alia to economic statistics, so much so that 108 eminent Indian economists released a joint statement last year warning that the statistical system was "being influenced and indeed even controlled by political considerations" (see Azad et al. 2019).

\section{References}

Alkire, S., Oldiges, C., and Kanagaratnam, U. (2018). Multidimensional poverty reduction in India 2005/62015/16: Still a long way to go but the poorest are catching up. Working paper, Oxford Poverty and Human Development Initiative (OPHI).

Anon (2019). Stagnation in rural wage rates. Review of Agrarian studies, 9.

Ascherio, A. et al. (1992). Effect of the Gulf War on infant and child mortality in Iraq. New England Journal of Medicine, 327(13):931-936.

Azad, R. et al. (2019). Economic statistics in shambles. Economic and Political Weekly, 54(11).

Bhat, P. M. (2002). Completeness of India's Sample Registration System: an assessment using the general growth balance method. Population studies, 56(2):119-134.

Canudas-Romo, V., Saikia, N., and Diamond-Smith, N. (2016). The contribution of age-specific mortality towards male and female life expectancy differentials in India and selected States, 1970-2013. Asia-Pacific Population Journal, 30(2):1-20. 
Deaton, A. (2013). The great escape: Health, wealth, and the origins of inequality. Princeton University Press.

Drèze, J. (2020). India is in denial about the covid-19 crisis. Scientific American. August 25.

Drèze, J. and Gazdar, H. (1992). Hunger and poverty in Iraq, 1991. World Development, 20(7):921-945.

Drèze, J., Kumar, D., and Ranjan, A. (2016). Demonetisation decimates Ranchi's economy. The Wire.

Drèze, J. and Paikra, V. (2020). The uneven decline of health services during lockdown. The Wire.

Drèze, J. and Sen, A. (2013). An uncertain glory: India and its contradictions. Princeton University Press.

Gerland, P. (2014). Un population division's methodology in preparing base population for projections: case study for india. Asian Population Studies, 10(3):274-303.

Gupta, A., Khalid, N., Deshpande, D., Hathi, P., Kapur, A., Srivastav, N., Vyas, S., Spears, D., and Coffey, D. (2020a). Revisiting open defecation. Economic and Political Weekly, 55(21).

Gupta, A., Vyas, S., Hathi, P., Khalid, N., Srivastav, N., Spears, D., and Coffey, D. (2020b). Persistence of solid fuel use in Rural North India. Economic \& Political Weekly, 55(3):55.

Hill, K., You, D., Inoue, M., and Oestergaard, M. Z. (2012). Child mortality estimation: Accelerated progress in reducing global child mortality, 1990-2010. PLoS Med, 9(8):e1001303.

Ho, J. Y. and Hendi, A. S. (2018). Recent trends in life expectancy across high income countries: retrospective observational study. BMJ, 362:k2562.

Jha, S. (2019a). Consumer spend sees first fall in 4 decades on weak rural demand: NSO data. Business Standard.

Jha, S. (2019b). Unemployment rate at four-decade high of 6.1\% in 2017-18: NSSO survey. Business Standard.

Kochanek, K. D., Maurer, J. D., and Rosenberg, H. M. (1994). Why did black life expectancy decline from 1984 through 1989 in the United States? American Journal of Public Health, 84(6):938-944.

Mahapatra, P. (2017). The Sample Registration System (SRS) in India, an overview, as of 2017. Working paper, Prince Mahidol Award Conference and Global Health Information Forum.

Narayanan, S. (2020). Economic survey 2019-20: How does it seek to address challenges of farm sector? Ideas for India.

ORGI (2013). Census of india 2011: Primary census abstract. Office of the Registrar and General Census Commissioner of India.

ORGI (2016a). Compendium of India's Fertility and Mortality Indicators 1971-2013 based on the Sample Registration System (SRS). Report, Office of the Registrar Genegral and Census Commissioner of India, New Delhi, Government of India.

ORGI (2016b). India Sample Registration System Baseline Survey 2014. report, Office of the Registrar General and Census Commissioner of India, Ministry of Home Affairs, Government of India New Delhi.

ORGI (2020). Sample registration system statistical report 2018. Report, Office of the Registrar General and Census Commissioner of India, New Delhi: Government of India.

Preston, S., Heuveline, P., and Guillot, M. (2001). Demography: Measuring and Modeling Population Processes. Malden, MA: Blackwell Publishers.

Reddy, C. R. (2019). Demonetisation and Black Money. Orient BlackSwan Private Limited.

Reniers, G., Masquelier, B., and Gerland, P. (2011). Adult mortality in Africa. In International handbook of adult mortality, pages 151-170. Springer.

Rosling, H., Rosling, O., and Rosling, A. R. (2019). Factfulness: Ten reasons why we are wrong about the world, and things are better than you think. Flammarion.

Rukmini S (2020). How covid-19 response disrupted health services in rural India. LiveMint.

Saikia, N., Singh, A., and Ram, F. (2010). Has child mortality in India really increased in the last two decades? Economic and Political Weekly, pages 62-70.

Shkolnikov, V. M., Cornia, G. A., Leon, D. A., and Meslé, F. (1998). Causes of the Russian mortality crisis: evidence and interpretations. World Development, 26(11):1995-2011.

Subramanian, S. (2020). What is happening to rural welfare, poverty, and inequality in India? Ideas for India. Vyas, M. (2018). Using fast frequency household survey data to estimate the impact of demonetisation on employment. Review of Market Integration, 10(3):159-183. 
Figure 1: Infant mortality trends in India, 1971-2018

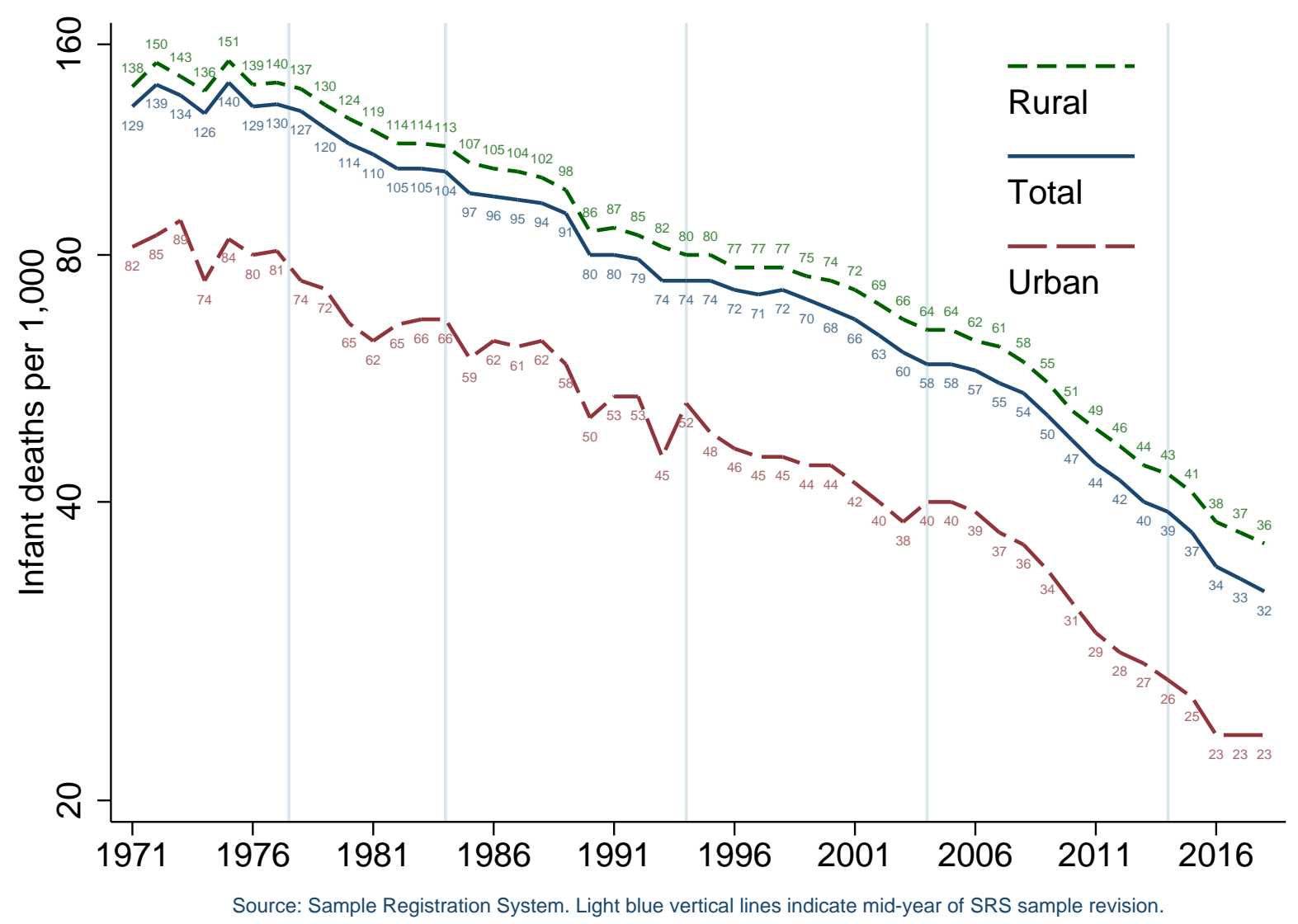


Figure 2: Infant mortality by state, 1988 - 2018

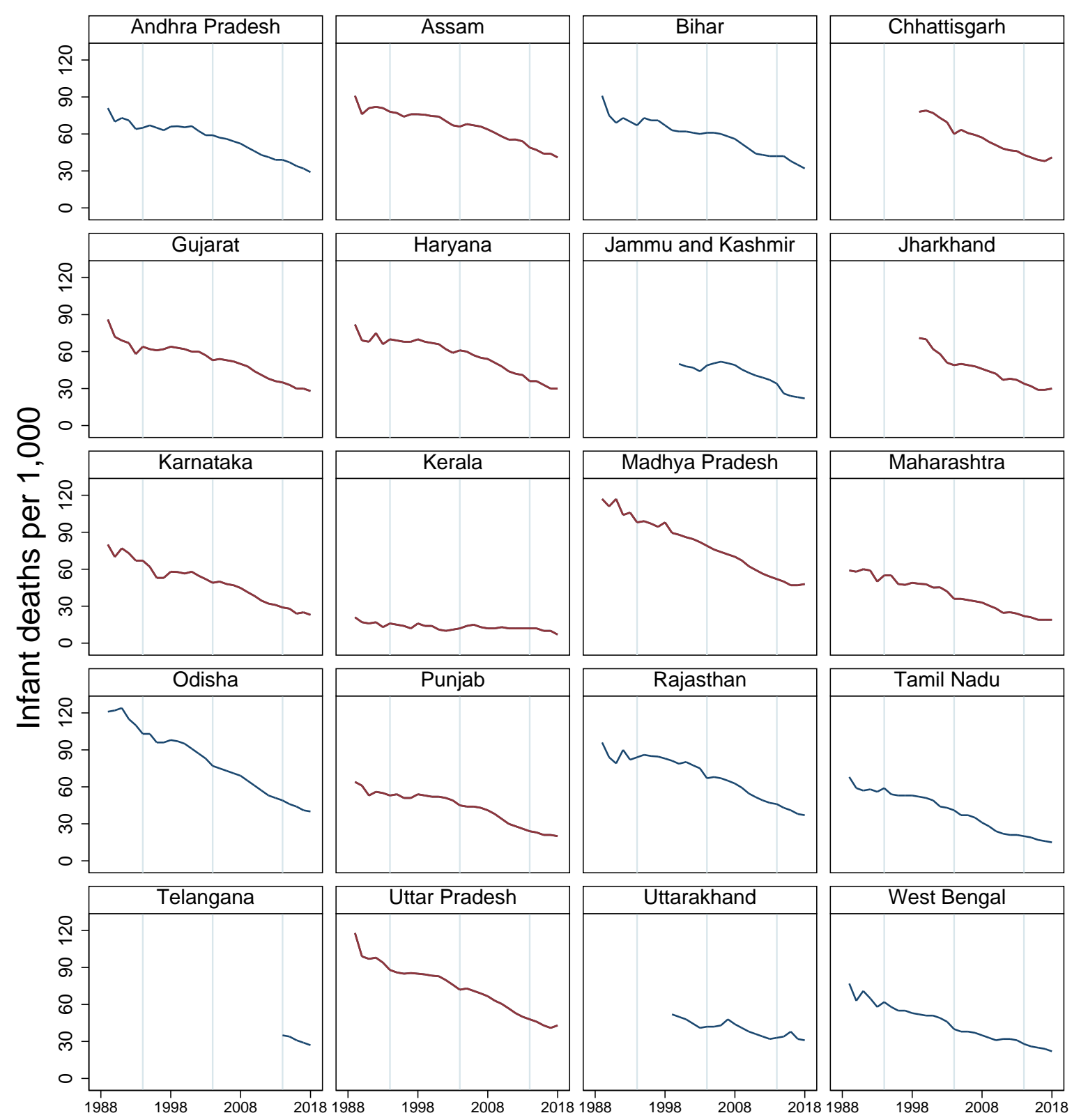

Note: States where IMR did not decline in 2017 or 2018 (compared to previous year) are shown in red. Light blue vertical lines indicate mid-year of SRS sample revision. 
Figure 3: Compared to 2016, more states saw increases in IMR in 2017 and 2018
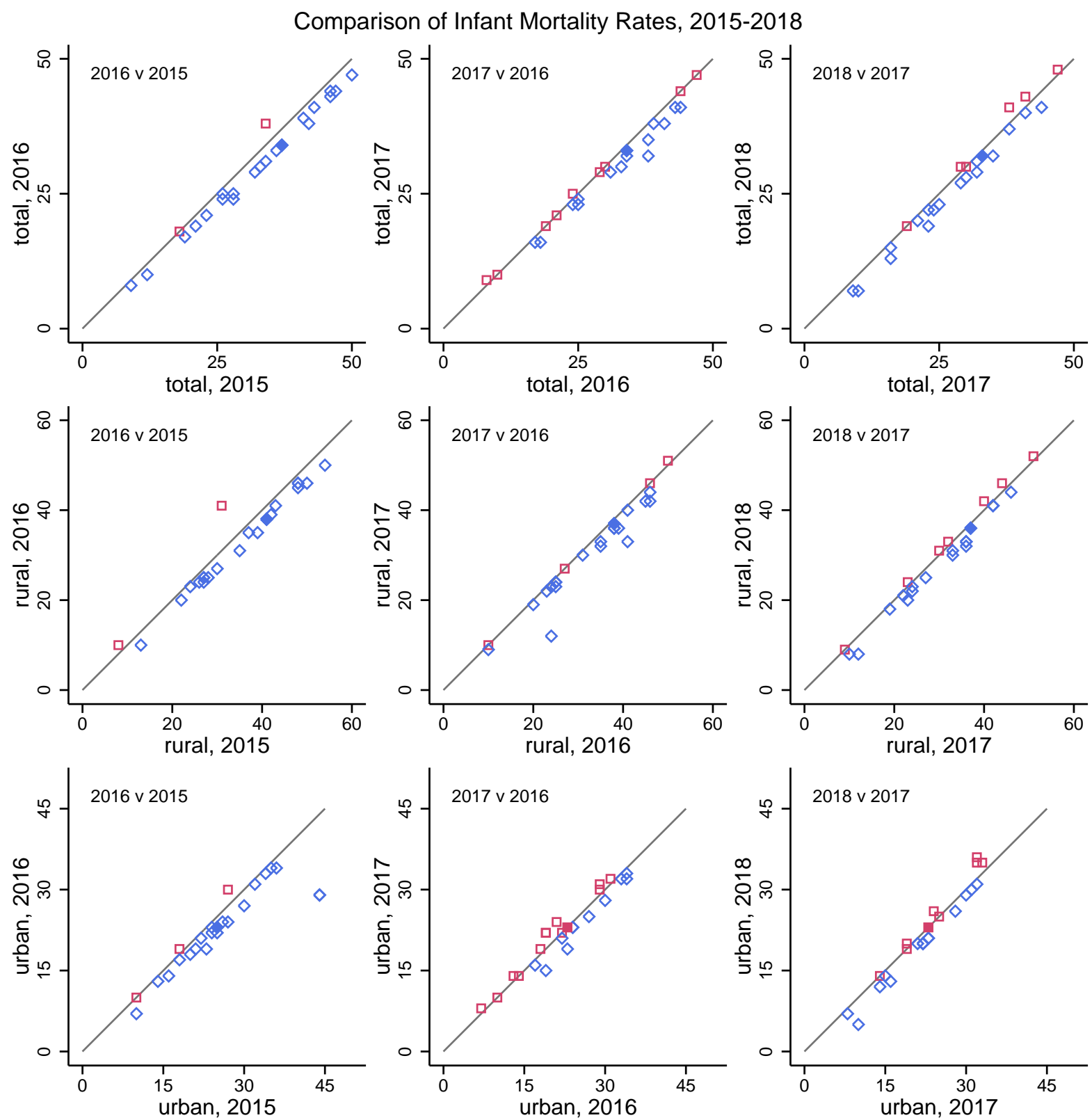

Note: Hollow red squares imply that the IMR in a state increased or remained the same.

Blue diamonds represent a decline. The grey line represents the $45^{\circ}$ line.

Solid squares and diamonds are for India. 


\section{APPENDIX}

This appendix presents some supplementary figures not discussed in detail in the text. Figure A1 shows age-specific mortality rates in the 0-1 age group (that is, deaths divided by person-years lived in the age group) from 2013 to 2018. It brings out a clear pattern of stagnation in 2017 and 2018, not only in urban areas but also, to a large extent, in rural areas.

Figures A2 and A3 show state-wise infant mortality trends in rural and urban areas, respectively. As noted in the text, infant mortality declines faltered in rural areas of 9 states (out of 20), and in urban areas of 15 states. Partly because of their smaller samples, statewise mortality trends in urban areas have higher variation, as well as a higher sensitivity to changes in the SRS sampling frame. Still, even with these fluctuations, trends in the last 15 years before 2016 had been relatively smooth even in urban areas. These graphs reinforce patterns commented on in section 2 , that infant mortality declines slowed-down, stagnated, or reversed in many parts of India. 
Figure A1: Age-specific mortality rate, 0-1, 2013 - 2018

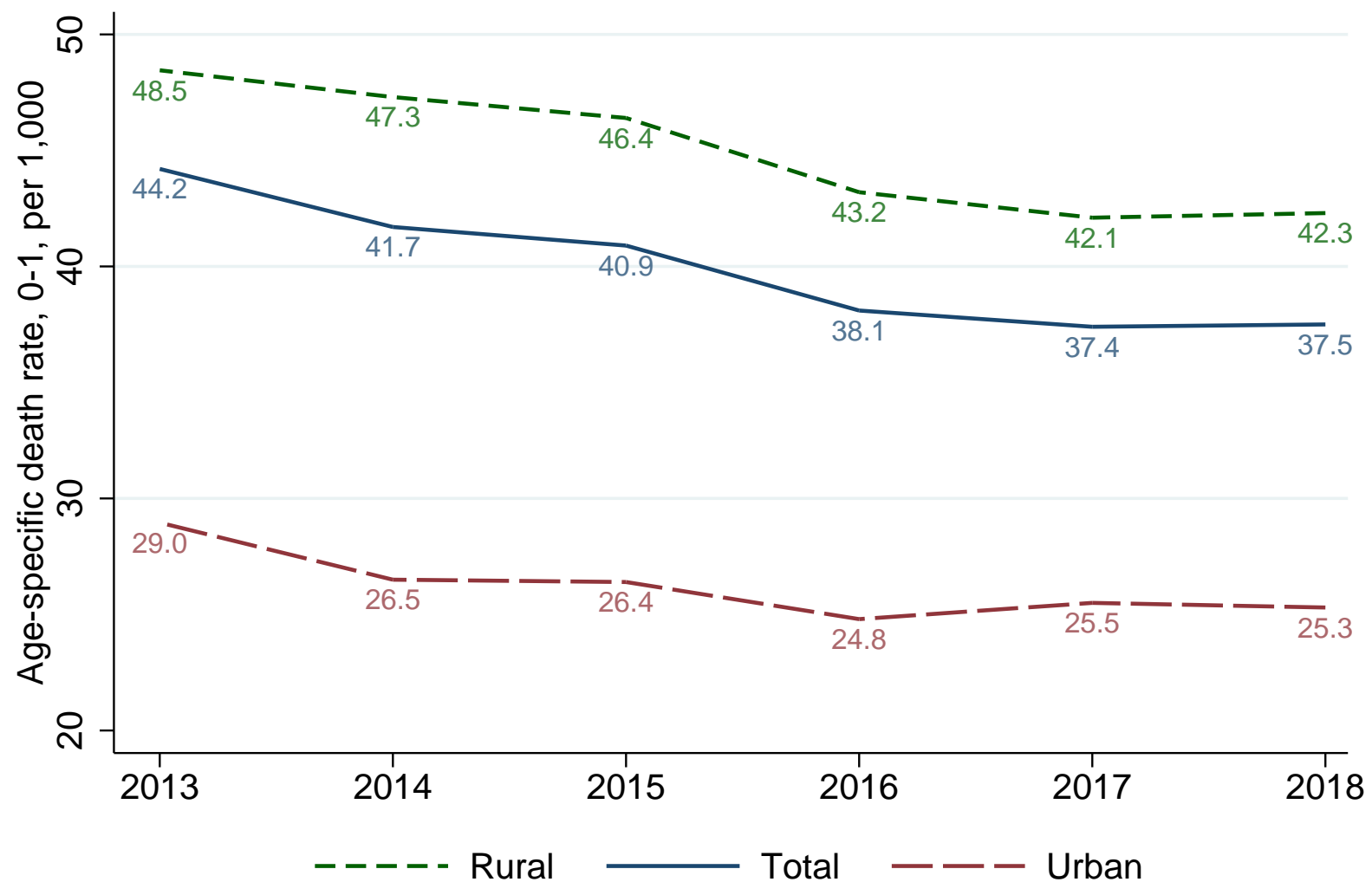

Source: Sample Registration System. 
Figure A2: Infant mortality by state, rural, 1988 - 2018

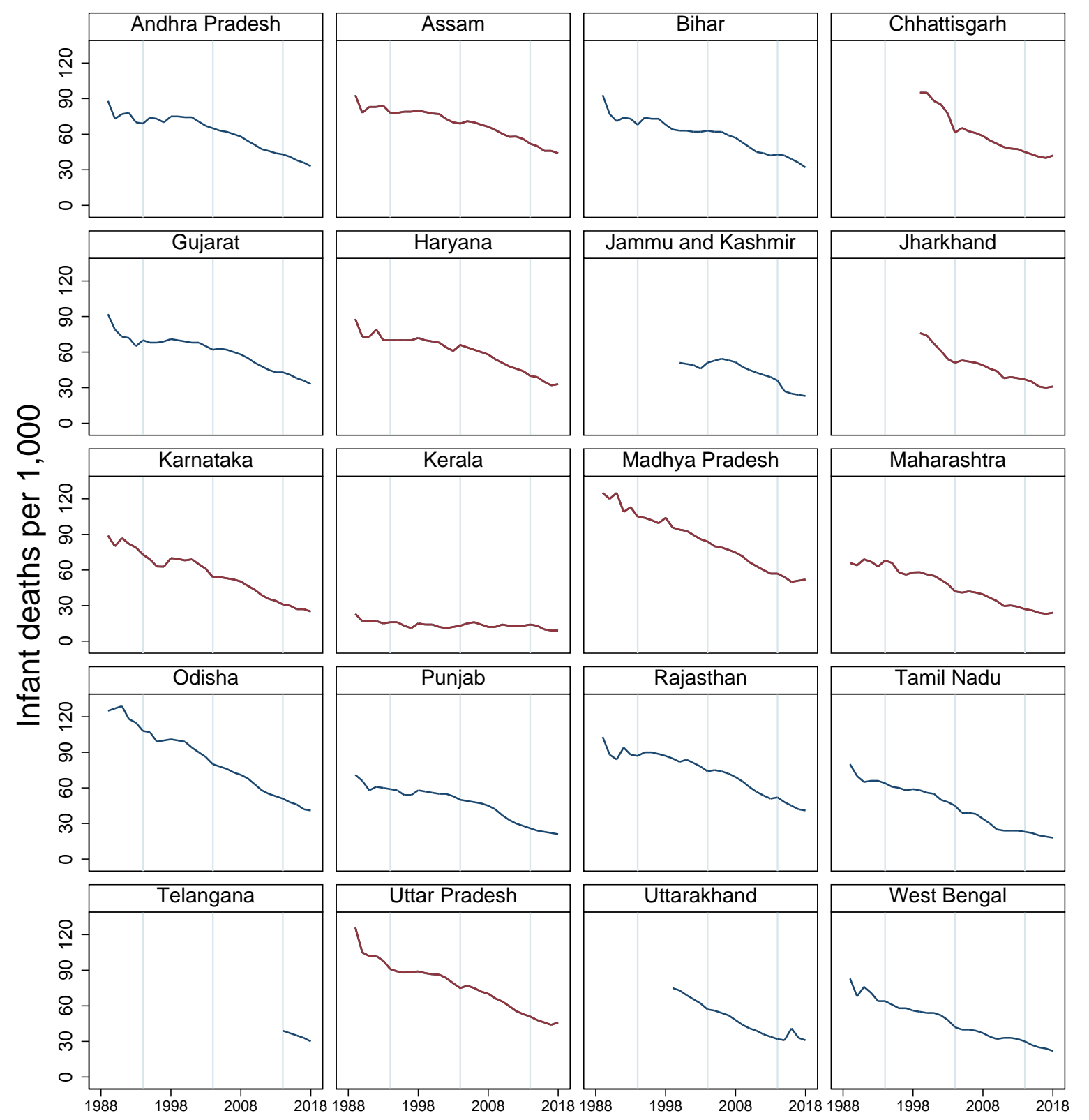

Note: States where IMR did not decline in 2017 or 2018 (compared to previous year) are shown in red. Light blue vertical lines indicate mid-year of SRS sample revision. 
Figure A3: Infant mortality by state, urban, 1988 - 2018

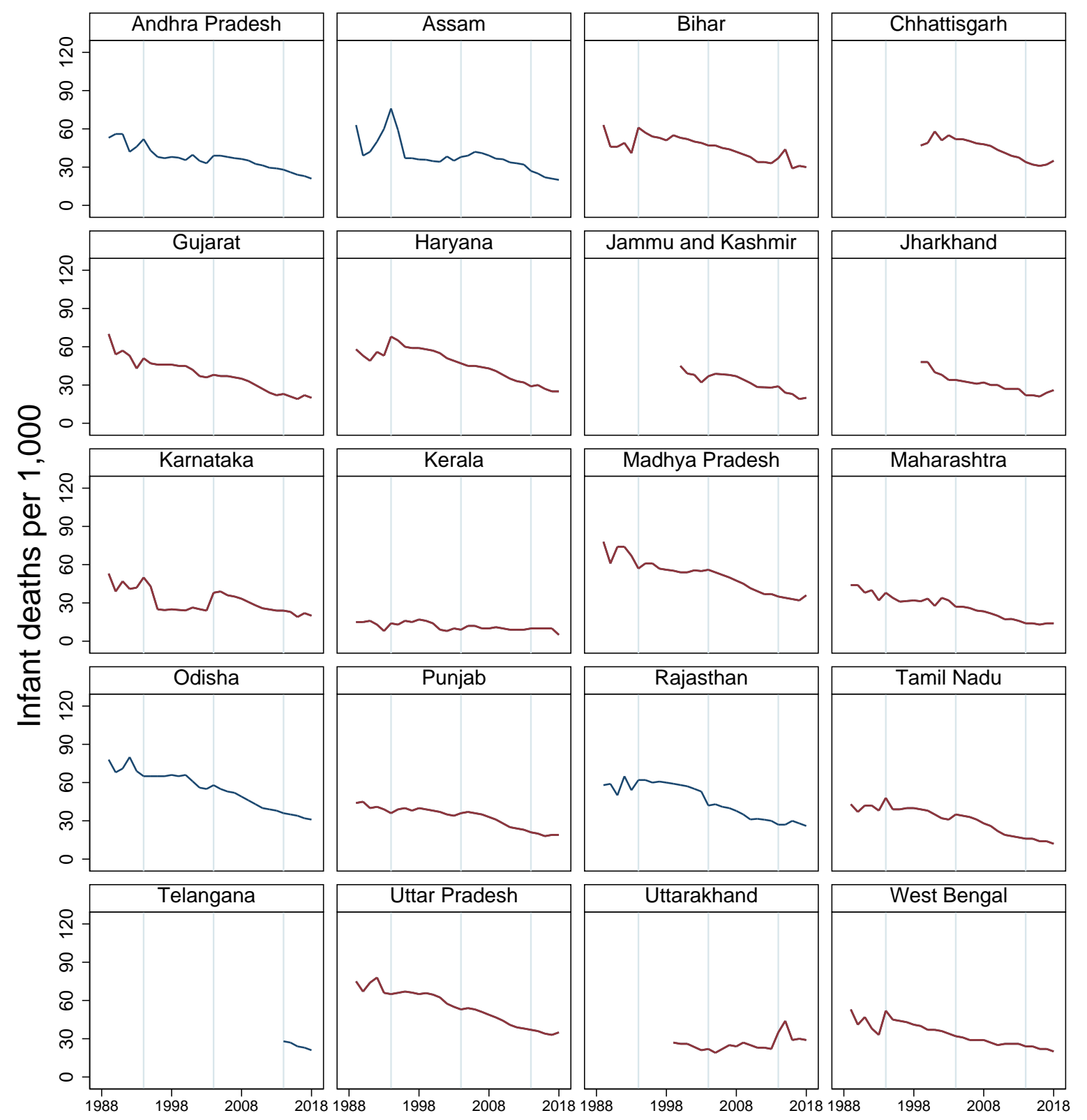

Note: States where IMR did not decline in 2017 or 2018 (compared to previous year) are shown in red. Light blue vertical lines indicate mid-year of SRS sample revision. 